\title{
The Western Denmark Cardiac Computed Tomography Registry: a review and validation study
}

This article was published in the following Dove Press journal:

Clinical Epidemiology

31 December 2014

Number of times this article has been viewed

\section{Lene Hüche Nielsen' \\ Bjarne Linde Nørgaard ${ }^{2}$ \\ Hans Henrik Tilsted ${ }^{3}$ \\ Niels Peter Sand ${ }^{4}$ \\ Jesper Møller Jensen² \\ Morten Bøttcher ${ }^{5}$ \\ Axel C Diederichsen ${ }^{6}$ \\ Jess Lambrechtsen ${ }^{7}$ \\ Lone Deibjerg Kristensen ${ }^{8}$ \\ Hans Mickley ${ }^{6}$ \\ Henrik Munkholm' \\ Ole Gøtzsche ${ }^{2}$ \\ Lars Lyhne Knudsen ${ }^{5}$ \\ Hans Erik Bøtker ${ }^{2}$ \\ Lars Pedersen? \\ Morten Schmidt 2,9}

'Department of Cardiology, Lillbaelt Hospital-Vejle, Vejle, Denmark;

${ }^{2}$ Department of Cardiology Aarhus University Hospital-Skejby, Aarhus,

Denmark; ${ }^{3}$ Department of Cardiology,

Aalborg University Hospital,

Aalborg, Denmark; ${ }^{4}$ Department of

Cardiology, Hospital of Southwestern

Denmark-Esbjerg, Esbjerg, Denmark;

${ }^{5}$ Department of Cardiology, Regional

Hospital Herning, Herning, Denmark;

${ }^{6}$ Department of Cardiology, Odense

University Hospital, Odense, Denmark;

${ }^{7}$ Department of Cardiology, Odense

University Hospital-Svendborg,

Svendborg, Denmark; ${ }^{8}$ Department of

Cardiology, Regional Hospital Silkeborg,

Silkeborg, Denmark; ${ }^{9}$ Department

of Clinical Epidemiology, Aarhus

University Hosptial, Aarhus, Denmark

Correspondence: Lene Hüche Nielsen Department of Cardiology,

Lillebaelt Hospital-Vejle, Kabbeltoft 25 ,

DK-7I 00 Vejle, Denmark

Email lenehuche@gmail.com
Background: As a subregistry to the Western Denmark Heart Registry (WDHR), the Western Denmark Cardiac Computed Tomography Registry (WDHR-CCTR) is a clinical database established in 2008 to monitor and improve the quality of cardiac computed tomography (CT) in Western Denmark.

Objective: We examined the content, data quality, and research potential of the WDHR-CCTR.

Methods: We retrieved 2008-2012 data to examine the 1) content; 2) completeness of procedure registration using the Danish National Patient Registry as reference; 3) completeness of variable registration comparing observed vs expected numbers; and 4) positive predictive values as well as negative predictive values of 19 main patient and procedure variables.

Results: By December 31, 2012, almost 22,000 cardiac CTs with up to 40 variables for each procedure have been registered. Of these, $87 \%$ were coronary CT angiography performed in patients with symptoms indicative of coronary artery disease. Compared with the Danish National Patient Registry, the overall procedure completeness was $72 \%$. However, an additional medical record review of 282 patients registered in the Danish National Patient Registry, but not in the WDHR-CCTR, showed that coronary CT angiographies accounted for only $23 \%$ of all nonregistered cardiac CTs, indicating $>90 \%$ completeness of coronary CT angiographies in the WDHR-CCTR. The completeness of individual variables varied substantially (range: $0 \%-100 \%$ ), but was $>85 \%$ for more than $70 \%$ of all variables. Using medical record review of 250 randomly selected patients as reference standard, the positive predictive value for the 19 variables ranged from $89 \%$ to $100 \%$ (overall $97 \%$ ), whereas the negative predictive value ranged from $97 \%$ to $100 \%$ (overall $99 \%$ ). Stratification by center status showed consistently high positive and negative predictive values for both university $(96 \% / 99 \%)$ and nonuniversity centers $(97 \% / 99 \%)$.

Conclusion: WDHR-CCTR provides ongoing prospective registration of all cardiac CTs performed in Western Denmark since 2008. Overall, the registry data have a high degree of completeness and validity, making it a valuable tool for clinical epidemiological research.

Keywords: coronary computed tomography angiography, database, epidemiology, registries

\section{Introduction}

Technological advances in computed tomography (CT) have facilitated the development of cardiac CT enabling rapid and accurate imaging of the cardiovascular system, including coronary arteries, coronary arterial wall, cardiac valves, myocardium, and associated structures. ${ }^{1}$ The primary clinical indication for cardiac CT is the detection or exclusion of coronary artery disease (CAD) in patients suspected of angina (ie, coronary CT angiography [CTA] $)^{2,3}$ As a subregistry of the Western Denmark 
Heart Registry (WDHR), ${ }^{4}$ the Western Denmark Cardiac Computed Tomography Registry (WDHR-CCTR) was established in $2008 .{ }^{5}$ In addition to monitoring and improving the cardiac CT quality in Western Denmark, the aim of the WDHR-CCTR is to allow for real-world clinical and health-service research. ${ }^{5}$ The coronary interventional data of the WDHR have previously been reviewed, ${ }^{4}$ whereas the cardiac CT data have not. We therefore examined the content, data quality, and research potential of the WDHR-CCTR, focusing particularly on the coronary CTA data.

\section{Methods}

\section{Setting}

Western Denmark has a population of 3.3 million (55\% of the total Danish population). The Danish National Health Service provides tax-supported health care for the entire Danish population including free access to hospitals, general practitioners and outpatient specialty clinics, and partial reimbursement of prescribed medications. ${ }^{6}$ The Danish Civil Registration System assigns a unique 10-digit Civil Personal Register (CPR) number to all residents at birth or upon immigration and records information on residents' vital and emigration status with daily update. ${ }^{7}$ The CPR number enables linkage between all registries in Denmark at the individual level. ${ }^{7}$

\section{Data registration}

The WDHR-CCTR is derived from an internet-based online system, running on an encrypted public net. ${ }^{4}$ A common interface form secures standardized data collection from the cardiac centers. ${ }^{4}$ To optimize the data quality, data are entered by the cardiac center at which the procedure is performed into a computer-based data management system using the patient's CPR number. ${ }^{4}$ Serial numbers for patients and procedures are automatically generated to protect patient confidentiality. Standardized forms are used for registration of data. Three registration forms (a referral form, a medical history form, and a procedural form) are completed when entering data into the WDHR-CCTR (Table S1).

\section{Study population}

As of 2014, all nine cardiac centers (three university and six nonuniversity centers) in Western Denmark report to the WDHR-CCTR (Figure 1). University cardiac centers are defined by performing coronary revascularization procedures. WDHR-CCTR previously included ten cardiac centers, but recently the two centers at Aarhus University Hospital (Skejby and Tage Hansens Gade) were merged into one center. The WDHR-CCTR includes information on adult
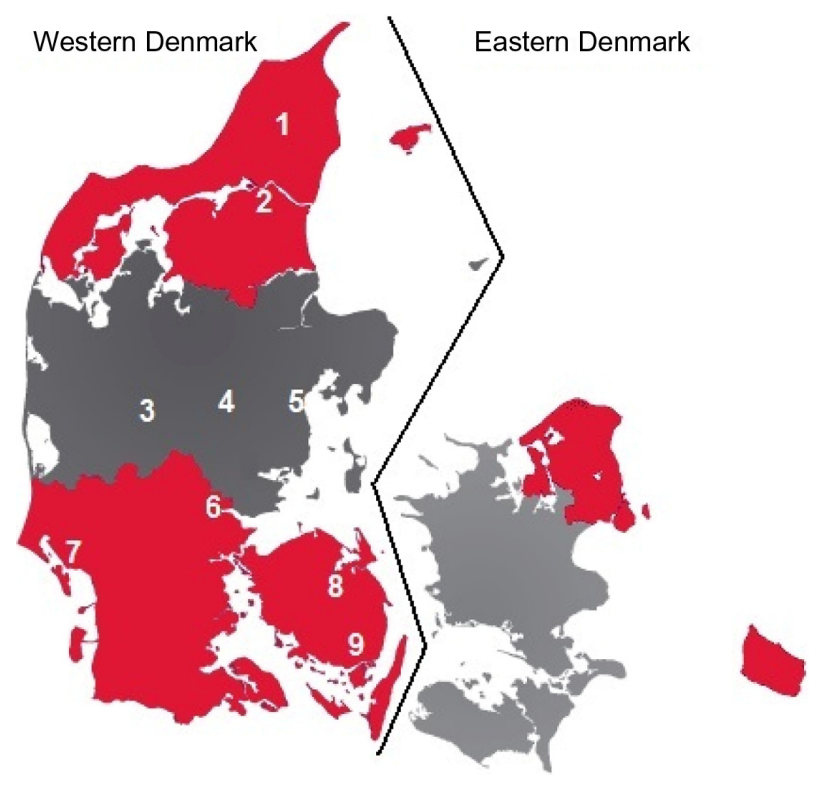

Figure I Cardiac centers reporting to Western Denmark Cardiac Computed Tomography Registry.

Notes: Color codings indicate the five regions of Denmark. Numbers indicate the cardiac centers reporting to the registry: (I) Vendsyssel Hospital; (2) Aalborg University Hospital; (3) Regional Hospital Herning; (4) Regional Hospital Silkeborg; (5) Aarhus University Hospital (previously comprising two separate cardiac centers); (6) Lillebaelt Hospital-Vejle; (7) Hospital of Southwestern Denmark-Esbjerg; (8) Odense University Hospital; and (9) Odense University Hospital-Svendborg Hospital.

patients ( $\geq 16$ years) referred for cardiac CT in Western Denmark. We included all patients registered between January 1, 2008, and December 31, 2012. In addition, we examined separately the subgroup of patients undergoing coronary CTA on suspicion of angina.

\section{Statistical analysis}

\section{Content}

We reviewed the variables recorded in the WDHR-CCTR and presented categorical variables using frequencies and proportions, and continuous variables using medians and interquartile ranges.

\section{Completeness}

By completeness of data, we refer to the proportion of registrations completed. Data completeness was evaluated at two levels: 1) completeness of procedure registrations and 2) completeness of variable registrations.

To estimate completeness of procedure registration, we used the Danish National Patient Registry (DNPR) as reference standard. Since 1977, all admissions to Danish hospitals have been registered in the DNPR using one primary discharge diagnosis and when appropriate secondary discharge diagnoses according to the International Classification of Disease (eighth revision through 1993 and the 
tenth revision thereafter). ${ }^{8}$ Outpatient specialty clinic visits have been included in the DNPR since 1995 and diagnostic procedures since $1999 .{ }^{8}$ Cardiac CT is coded in the DNPR according to the Nordic Medical Statistics Committees Classification of Surgical Procedures (code: UXCC00A). ${ }^{9}$ The DNPR forms the basis for hospitals financial reimbursement, and hence, the completeness of procedure registrations in the DNPR is likely high. We therefore considered the DNPR an appropriate reference standard.

The completeness of procedure registration in the WDHR-CCTR was calculated as the proportion of patients registered with a cardiac CT in the DNPR from hospitals in Western Denmark that was also registered in the WDHRCCTR. ${ }^{10}$ Of note, coronary and noncoronary CTAs are not registered separately in the DNPR. Therefore, to evaluate the degree of underregistration of coronary and noncoronary CTAs in the WDHR-CCTR in WDHR-CCTR, we reviewed the medical records from all patients $(n=282)$ who had cardiac CT registered in the DNPR, but not in the WDHR-CCTR during 2008-2012 at Aarhus University Hospital and Lillebaelt Hospital-Vejle.

The completeness of the individual variables was calculated as the number of patients with information on the variable divided by the total number of patients registered in the WDHR-CCTR. If patients underwent more than one cardiac CT within the study period, only data from the first procedure were included in the analyses.

\section{Validity}

For variable validation, we included only coronary CTAs because it is by far the most common indication for cardiac $\mathrm{CT}$ and the only one reported consecutively to the WDHRCCTR since its establishment. We assessed the validity of the WDHR-CCTR data through review of hospital medical records (both paper and electronic files). A computergenerated random sample of 250 patients from five different centers ( 50 patients from each center) was drawn. We selected patients from both university (Aarhus, Aalborg, and Odense) and nonuniversity cardiac centers (Lillebaelt Hospital-Vejle and Hospital of Southwestern Denmark-Esbjerg). Within each cardiac center, patients were selected randomly regardless of whether data were missing on one or more variables. Correlating with the increasing number of procedures performed since 2008 , the random sample included $4.8 \%$ of all patients from 2008, $13.6 \%$ from 2009, 26.0\% from 2010 , $26.4 \%$ from 2011, and 29.2\% from 2012.

For each procedure, we selected 19 main patient and procedure variables (Table S1). One clinician (LHN) reviewed all medical records. During validation, one of three outcomes was recorded: confirmed by medical record, not confirmed by medical record, or missing in medical record. To facilitate calculation of predictive values also for continuous variables and variables with more than two categories, the registry data were considered confirmed in the medical records only when there was an exact match between the variable values in the registry and medical records. We considered the procedure date correct if the differences between the dates in the WDHR-CCTR and the medical records were $<1$ week.

We constructed a $2 \times 2$ table with results for the true-positive, false-positive, false-negative, and true-negative scores, enabling calculation of positive predictive values (PPVs) and negative predictive values (NPVs) for each variable. PPV was defined as the number of true positives/(number of true positives + number of false positives). NPV was defined as the number of true negatives/(number of true negatives + number of false negatives). We used Wilson's score methods to calculate confidence intervals (CIs). ${ }^{11}$

Patients with missing information in the medical files on a specific variable were omitted from the calculation of PPV and NPV. However, because missingness potentially could be associated with the accuracy of variable registration, we repeated the analyses by including all missing medical records as confirmed (best-case scenario) and nonconfirmed (worst-case scenario) cases in the calculations. Finally, we stratified the predictive values by cardiac center status and calendar year. All analyses were performed with STATA (version 13.0). The present study was approved by the Danish Data Protection Agency (2008-58-0035), and the National Board of Health (Department of Monitoring and Patient Safety) approved access to medical records (3-3013-377).

\section{Results Content}

During 2008-2012, we identified 21,623 patients registered with a cardiac CT in the WDHR-CCTR. Of these, $1.5 \%$ underwent more than one procedure. Among all patients, 18,899 patients underwent a coronary CTA $(87 \%)$. The annual number of patients examined by coronary CTA increased from 369 patients in 2008 to 6,454 patients in 2012. The characteristics of the cardiac CT and the coronary CTA cohorts are provided in Table 1.

\section{Completeness}

Throughout the study period, a consistently higher number of cardiac CTs were registered in the DNPR than in the WDHR-CCTR (Figure 2). The proportion of patients 
Table I Patient characteristics and variable completeness in the Western Denmark Cardiac Computed Tomography Registry, 2008-2012

\begin{tabular}{|c|c|c|c|c|}
\hline & \multicolumn{2}{|c|}{ Frequency of characteristics } & \multicolumn{2}{|c|}{ Variable completeness, $\%$} \\
\hline & $\begin{array}{l}\text { Cardiac CT } \\
\text { cohort overall } \\
(n=21,623)\end{array}$ & $\begin{array}{l}\text { Coronary } \\
\text { CTA cohort } \\
(n=\mid 8,899)\end{array}$ & $\begin{array}{l}\text { Cardiac } \\
\text { CT cohort } \\
\text { overall }\end{array}$ & $\begin{array}{l}\text { Coronary } \\
\text { CTA } \\
\text { cohort }^{\mathrm{a}}\end{array}$ \\
\hline Male sex & $10,169(47.0)$ & $8,506(45.0)$ & 100 & 100 \\
\hline Age, years ${ }^{\mathrm{b}}$ & $58(50-66)$ & $58(50-66)$ & 100 & 100 \\
\hline County & - & - & 97.1 & 97.6 \\
\hline Area code & - & - & 97.1 & 97.6 \\
\hline Referral date & - & - & 78.7 & 77.2 \\
\hline Family history of premature CAD & $8,044(37.2)$ & $7,353(38.9)$ & 85.7 & 82.7 \\
\hline Current lipid-lowering therapy & $6,589(30.5)$ & $5,883(31.1)$ & 85.6 & 85.5 \\
\hline Current medical treatment for hypertension & $7,400(34.2)$ & $6,532(34.6)$ & 85.5 & 85.3 \\
\hline Smoking status (current or former) & $10,648(49.2)$ & $9,504(50.3)$ & 85.9 & 85.8 \\
\hline Diabetes & $\mathrm{I}, 208(5.6)$ & $1,035(5.5)$ & 85.9 & 85.4 \\
\hline Previous $\mathrm{PCl}$ & $278(1.3)$ & $166(0.9)$ & 85.9 & 86.2 \\
\hline Previous cardiac surgery & $354(1.6)$ & $156(0.8)$ & 85.9 & 87.0 \\
\hline Previous myocardial infarction & $310(1.4)$ & $193(1.0)$ & 85.9 & 86.1 \\
\hline Height $(\mathrm{cm})^{\mathrm{b}}$ & $172(165-178)$ & $|7|(\mid 65-178)$ & 79.5 & 80.6 \\
\hline Weight $(\mathrm{kg})^{\mathrm{b}}$ & $78(67-89)$ & $78(67-88)$ & 79.8 & 80.9 \\
\hline Creatinine level, $\mu \mathrm{mol} / \mathrm{L}^{\mathrm{b}}$ & $73(64-84)$ & $73(63-83)$ & 77.8 & 78.8 \\
\hline Systolic blood pressure, $\mathrm{mmHg}^{\mathrm{b}}$ & $140(126-151)$ & $140(126-151)$ & 77.6 & 78.9 \\
\hline Diastolic blood pressure, $\mathrm{mmHg}^{\mathrm{b}}$ & $81(75-90)$ & $81(75-90)$ & 77.5 & 78.8 \\
\hline Left ventricular ejection fraction ${ }^{\mathrm{b}}$ & $60(60-60)$ & $60(60-60)$ & 58.2 & 59.7 \\
\hline Type of CT scanner & - & - & 98.5 & 99.7 \\
\hline Cardiac CT indication & - & - & 99.6 & 100 \\
\hline Angina/equivalent & $18,899(87.4)$ & - & - & - \\
\hline Heart failure & $292(1.4)$ & - & - & - \\
\hline Visualization of valves and/or aorta disease & $239(1.1)$ & - & - & - \\
\hline Visualization of stents & $71(0.3)$ & - & - & - \\
\hline Evaluation of cardiac structures & $631(2.9)$ & - & - & - \\
\hline Others & $\mathrm{I}, 4 \mathrm{IO}(6.5)$ & - & - & - \\
\hline Unknown & $8 \mathrm{I}(0.4)$ & - & - & - \\
\hline Angina type (if any) & - & - & 61.4 & 70.3 \\
\hline Typical angina & - & $1,764(9.4)$ & - & - \\
\hline Atypical angina & - & $5,844(30.9)$ & - & - \\
\hline Unspecific chest pain & - & $4,760(25.2)$ & - & - \\
\hline Dyspnea & - & $916(4.8)$ & - & - \\
\hline Unknown & - & $5,615(29.7)$ & - & - \\
\hline Priority & - & - & 93.9 & 95.5 \\
\hline Acute & $118(0.5)$ & $78(0.4)$ & - & - \\
\hline Subacute & $860(4.0)$ & $755(4.0)$ & - & - \\
\hline Elective & $19,317(89.3)$ & I7,209 (9I.I) & - & - \\
\hline Unknown & $1,328(6.2)$ & $857(4.5)$ & - & - \\
\hline Date of procedure & - & - & 100 & 100 \\
\hline Kilo-electron volt ${ }^{\mathrm{b}}$ & $100(100-120)$ & $100(100-120)$ & 97.2 & 98.4 \\
\hline Radiation dose & $-^{c}$ & $-^{c}$ & 93.8 & 94.8 \\
\hline lodine concentration, $\mathrm{mg} / \mathrm{mL}^{\mathrm{b}}$ & $350(350-370)$ & $350(350-370)$ & 93.0 & 94.6 \\
\hline Contrast volume, $\mathrm{mL}^{\mathrm{b}}$ & $80(70-90)$ & $80(70-90)$ & 92.9 & 94.5 \\
\hline Preprocedural beta-blocker & $13,007(60.2)$ & $|1,99|(63.4)$ & 93.4 & 95.1 \\
\hline Heart rhythm & - & - & 93.5 & 95.2 \\
\hline Sinus rhythm & 19,855 (91.8) & I7,794 (94.2) & - & - \\
\hline Atrial fibrillation & $266(1.2)$ & $108(0.6)$ & - & - \\
\hline Other & $106(0.5)$ & $85(0.4)$ & - & - \\
\hline Unknown & $\mathrm{I}, 396(6.5)$ & $912(4.8)$ & - & - \\
\hline Heart rate, bpm ${ }^{\mathrm{b}}$ & $59(54-65)$ & $59(54-64)$ & 93.4 & 95.0 \\
\hline Cardiac CT quality & - & - & 88.9 & 90.1 \\
\hline Good & $16,120(74.6)$ & 14,304 (75.7) & - & - \\
\hline Moderate & $2,170(10.0)$ & $\mathrm{I}, 897(10.0)$ & - & - \\
\hline
\end{tabular}


Table I (Continued)

\begin{tabular}{|c|c|c|c|c|}
\hline & \multicolumn{2}{|c|}{ Frequency of characteristics } & \multicolumn{2}{|c|}{ Variable completeness, \% } \\
\hline & $\begin{array}{l}\text { Cardiac CT } \\
\text { cohort overall } \\
(n=21,623)\end{array}$ & $\begin{array}{l}\text { Coronary } \\
\text { CTA cohort } \\
(n=\mid 8,899)\end{array}$ & $\begin{array}{l}\text { Cardiac } \\
\text { CT cohort } \\
\text { overall }\end{array}$ & $\begin{array}{l}\text { Coronary } \\
\text { CTA } \\
\text { cohort }^{\mathrm{a}}\end{array}$ \\
\hline Nonevaluable & $923(4.3)$ & $828(4.4)$ & - & - \\
\hline Unknown & $2,410(11.1)$ & I,870 (9.9) & - & - \\
\hline CACS (Agatston) result ${ }^{\mathrm{b}}$ & $0(0-95)$ & $0(0-90)$ & 87.8 & 87.2 \\
\hline Coronary CTA result & - & - & 95.4 & 96.2 \\
\hline Normal & $|3,90|(64.3)$ & $12,550(66.4)$ & - & - \\
\hline Nonobstructive CAD & $2,573($ (II.9) & $2,213(11.7)$ & - & - \\
\hline I-vessel obstructive CAD & $2,176(10.1)$ & $2,012(10.6)$ & - & - \\
\hline 2-vessel obstructive CAD & $739(3.4)$ & $673(3.6)$ & - & - \\
\hline 3-vessel/LM obstructive CAD & $462(2.1)$ & $312(1.7)$ & - & - \\
\hline Only CACS performed & $778(3.6)$ & $427(2.3)$ & - & - \\
\hline Unknown & $994(4.6)$ & $712(3.7)$ & - & - \\
\hline Consequence of cardiac $\mathrm{CT}$ results & - & - & 86.2 & 86.7 \\
\hline Nothing further & $9,966(46.1)$ & $8,673(45.9)$ & - & - \\
\hline Medical treatment & $3,820(17.7)$ & $3,313(17.5)$ & - & - \\
\hline Referral to invasive coronary angiography & $3,520(16.3)$ & $3,216(17.0)$ & - & - \\
\hline Referral to myocardial perfusion imaging & $679(3.1)$ & $632(3.3)$ & - & - \\
\hline CACS is too high - referral to further testing & $199(0.9)$ & $157(0.8)$ & - & - \\
\hline Referral to other noninvasive diagnostic testing & $46 I(2.1)$ & $399(2.1)$ & - & - \\
\hline Unknown & $2,977(13.8)$ & $2,509(13.4)$ & - & - \\
\hline
\end{tabular}

Notes: aPatients with angina suspicious symptoms; ${ }^{b}$ values in median \pm interquartile range; ${ }^{c}$ was not estimated due to differences in registered dose units.

Abbreviations: CACS, coronary artery calcium scoring; CAD, coronary artery disease; CT, computed tomography; CTA, computed tomography angiography; LM, left main; $\mathrm{PCl}$, percutaneous coronary intervention.

registered with a cardiac CT in the DNPR and who also were registered in the WDHR-CCTR was overall $72 \%$ $(20,560 / 28,566)$ (Figure 3). Thus, 8,006 cardiac CTs were registered in the DNPR, but not in the WDHR-CCTR. The completeness of cardiac CT registration in the WDHR-CCTR improved, however, from $17 \%(378 / 2,233)$ in 2008 to $82 \%$ $(7,271 / 8,837)$ in 2012 (Figure 3).

The medical record review of the cardiac CTs registered in the DNPR but not in the WDHR-CCTR revealed that $79 \%$ $(192 / 244)$ of the procedures at Aarhus University Hospital

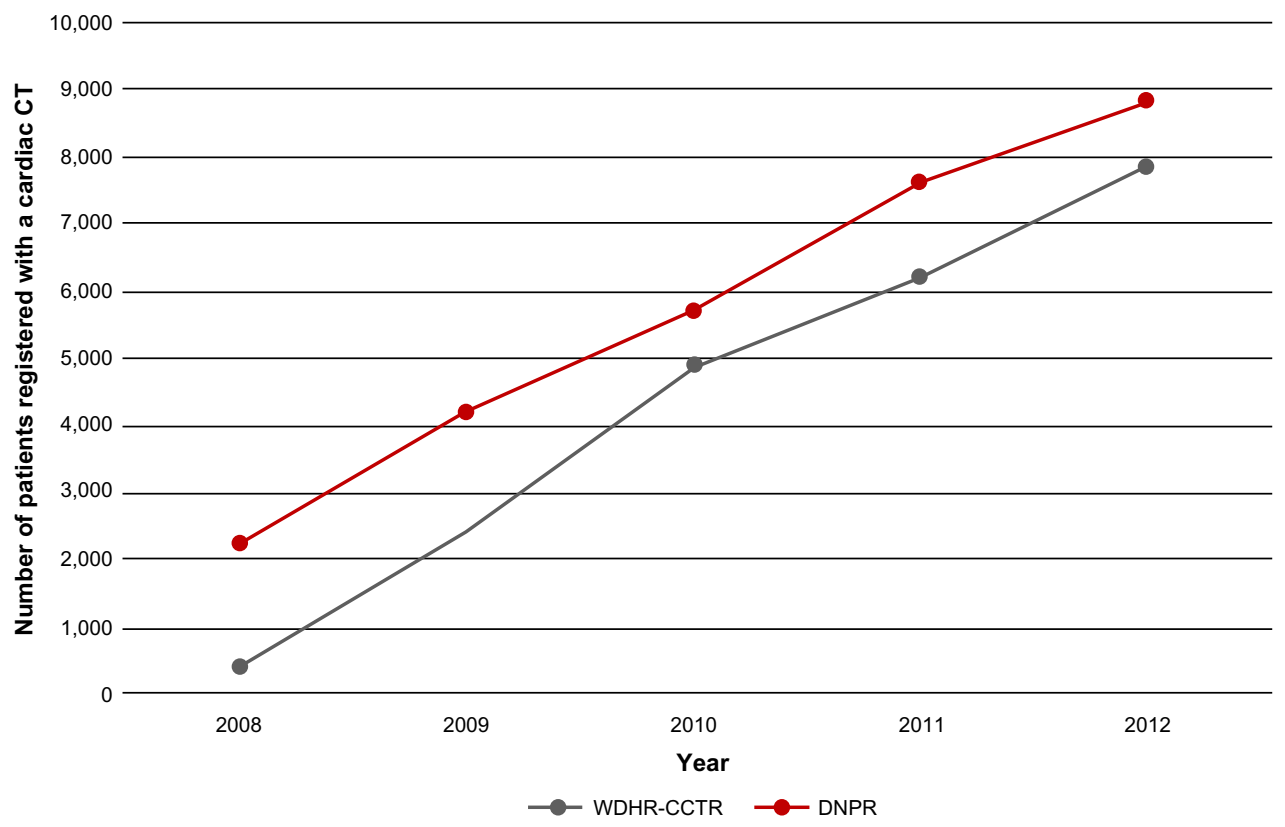

Figure 2 Number of patients having cardiac computed tomography (CT) registered in the Western Denmark Cardiac Computed Tomography Registry (WDHR-CCTR) and the Danish National Patient Registry (DNPR), 2008-20I2. 


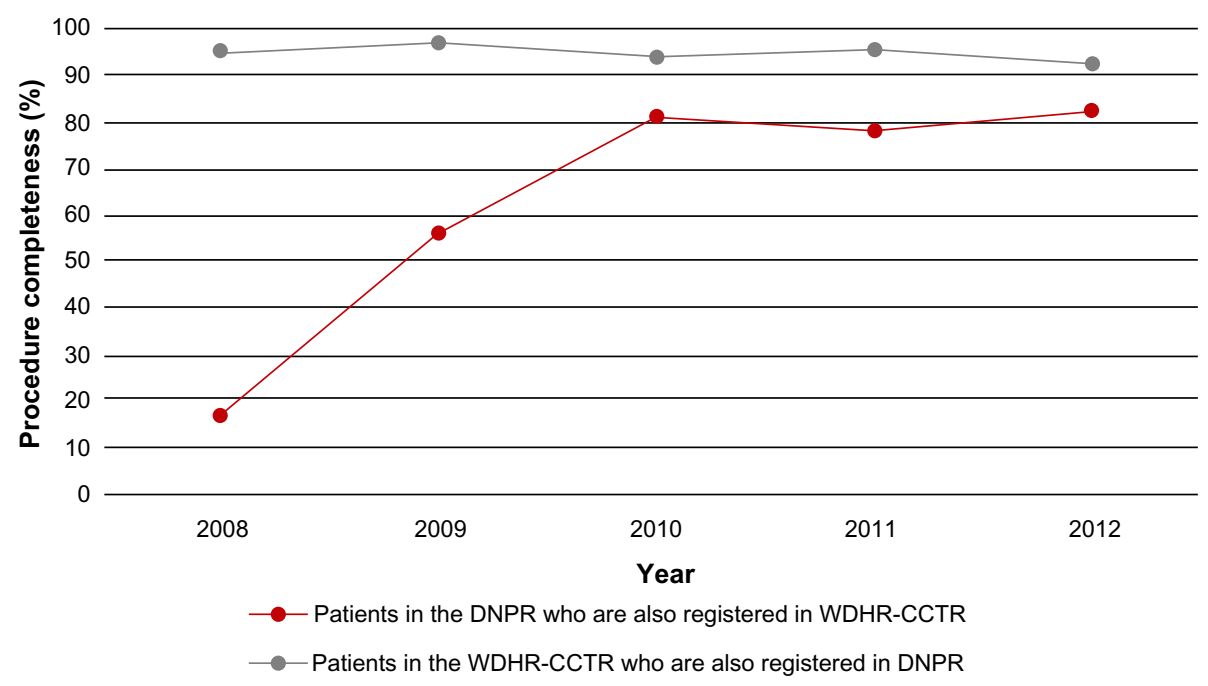

Figure 3 Proportion of patients having a cardiac computed tomography registered in both the Western Denmark Cardiac Computed Tomography Registry (WDHR-CCTR) and the Danish National Patient Registry (DNPR) during 2008-20I2.

and 66\% (25/38) at Lillebaelt Hospital-Vejle were performed on indications other than for coronary assessment in symptomatic patients (overall 77\%). These indications included coronary CTA in asymptomatic patients (heart failure and preoperative evaluation) and evaluation of cardiac anatomy (congenital heart disease, planning of electrophysiological procedures, or trans-catheter aortic valve replacement). Among the later procedures, approximately two-thirds were performed as part of research projects. Assuming the proportion of missing coronary CTA procedures in our sample (23\%) could be extrapolated to all 8,006 missing cardiac CTs in the WDHR-CCTR, the completeness of coronary CTA procedures reported to the WDHR-CCTR registry was approximately $91 \%(18,899 /(18,899+1,841))$. A secondary finding from the medical record review was that all the cardiac CTs registered in the DNPR had actually been performed (282/282), yielding a PPV for cardiac CT in the DNPR of 100\% (95\% CI: 98.7\%-100\%).

The completeness of individual variables is shown in Table 1 . The completeness ranged from $60 \%$ for the registration of left ventricular ejection fraction to $100 \%$ for CPR number, sex, age, and date of procedure. The completeness was $\geq 85 \%$ in more than two-thirds $(71 \%)$ of all variables.

\section{Validity}

All 250 medical records requested from the five selected cardiac centers were available for review and thus were included in the validation. The variables and reference standards used for the validation are provided in Table S2. Patients in the random sample had a higher prevalence of diabetes mellitus when compared with the total coronary
CTA cohort. Otherwise, the patient and CT procedural characteristics were similar to the overall coronary CTA cohort, indicating that the random sample was representative (Table S3). Among the 250 patients, 61\% (152/250) had complete data without missing values of any variables. A total of $7 \%(349 / 4,750)$ of variable values were missing in the WDHR-CCTR, of which 45\% (157/349) also were missing in the medical records.

The PPV ranged from 89\% (95\% CI: 81\%-94\%) for family history of premature CAD to $100 \%$ for previous cardiac surgery (95\% CI: 21\%-100\%) and coronary CTA indication (95\% CI: 98.5\%-100\%) (Table 2).

The NPV (when calculation was possible) ranged from 97\% (95\% CI: 91\%-100\%) for smoking status to $100 \%$ for previous myocardial infarction (95\% CI: 98\%-100\%) and previous percutaneous coronary intervention (95\% CI: 98\%-100\%) (Table 2). Stratification by university status showed consistently high overall predictive values (PPV/ NPV) for both university (96\%/99\%) and nonuniversity cardiac centers $(97 \% / 99 \%)$.

Less than $9 \%$ of the data in the random sample could not be verified from the medical records due to missing information. The variables that were least obtainable from the medical records were height $(143 / 228=62.3 \%)$ and weight $(142 / 228=62.3 \%)$ (Table 2$)$. With the exception of family history of premature CAD (76\%, 95\% CI: 76\%-84\%), height (33.5\%, 95\% CI: $28 \%-40 \%)$, and weight (34\%, 95\% CI: 28\%-41\%), the PPVs remained consistently high also in worst-case scenarios where all missing records were included as nonconfirmed cases. The NPVs also remained high in the worst-case scenarios. 


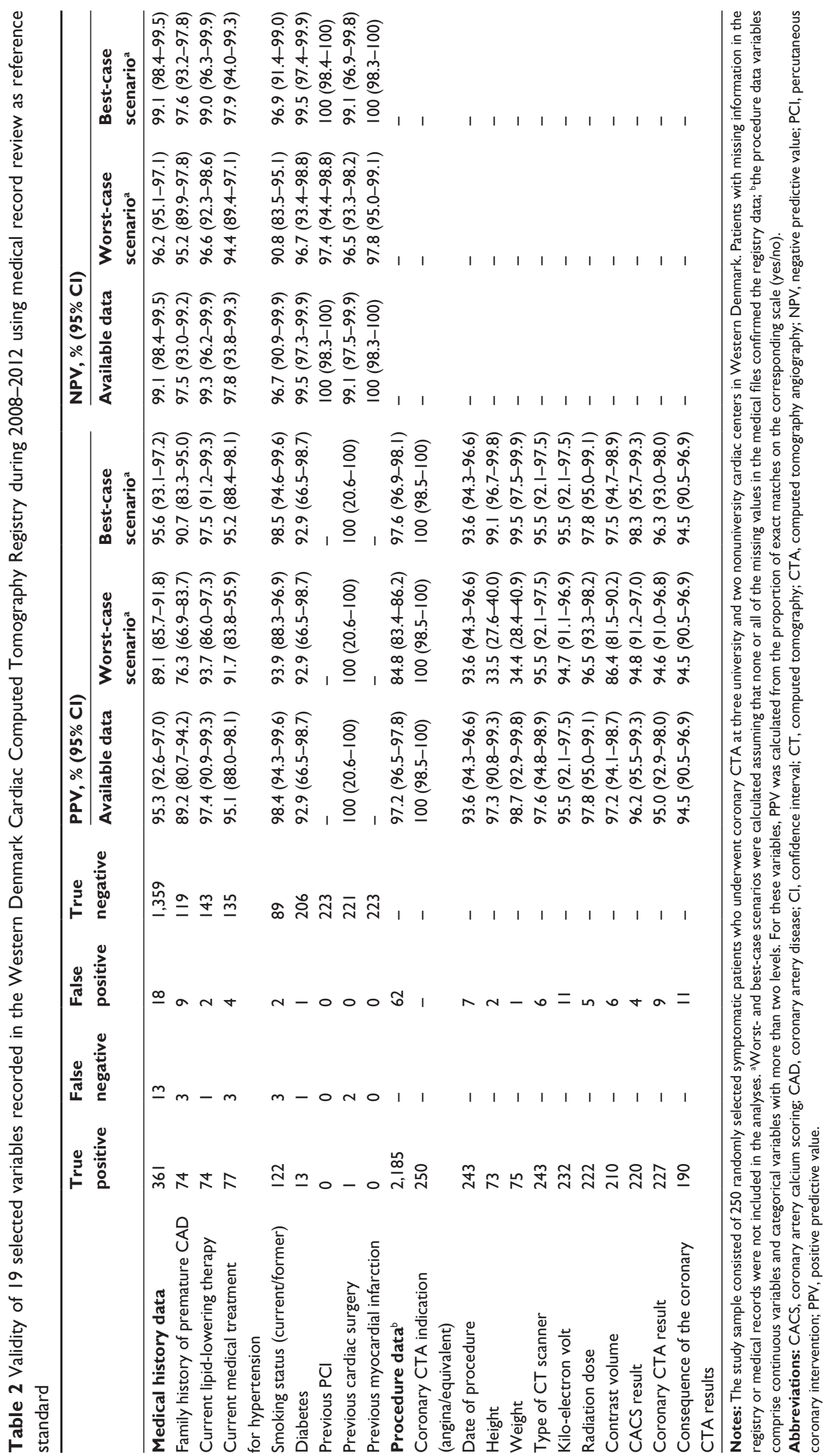


Stratification by calendar year (before 2010 vs 2010 and later) showed that the PPV improved for diabetes from $83 \%$ (95\% CI: $35 \%-97 \%$ ) to $100 \%$ (95\% CI: 69\%-100\%), for date of procedure from $73 \%$ (95\% CI: $64 \%-80 \%)$ to $96 \%$ (95\% CI: $92 \%-98.5 \%$ ), and for consequence of coronary CTA from 92\% (95\% CI: $84 \%-96 \%)$ to $97 \%$ (95\% CI: $92 \%-99 \%)$. In contrast, the PPV decreased for current medical treatment for hypertension from 97\% (95\% CI: $86 \%-99.5 \%$ ) to $93 \%$ (95\% CI: $82 \%-98 \%$ ) and for kilo-electron volt from $98 \%$ (95\% CI: $94 \%-99 \%$ ) to $93 \%$ (95\% CI: $88 \%-96.5 \%)$ ). Over the same period, the NPV for family history of premature CAD increased from 94\% (95\% CI: $86 \%-98 \%$ ) to $100 \%$ (95\% CI: $94 \%-100 \%$ ) and for current medical treatment for hypertension from $96.5 \%$ (95\% CI: $88 \%-100 \%$ ) to $98.8 \%$ (95\% CI: 93\%-100\%). For the other variables, the predictive values remained fairly constant over time.

\section{Discussion}

In this first review and validation of the WDHR-CCTR, we demonstrated that the registry as of 2012 includes data on approximately 22,000 patients undergoing cardiac CT. Among these, nearly 19,000 were for coronary assessment in patients with symptoms suggestive of CAD. Importantly, the yearly number of procedures and the completeness of data registration have increased consistently since the establishment of the registry in 2008. Although the overall completeness of cardiac CT procedures in the WDHR-CCTR compared with the DNPR was $72 \%$, additional subanalysis indicated that the completeness of coronary CTAs was more than $90 \%$. Although the completeness of individual variables differed substantially, it was high for the vast majority of variables. Finally, we found that the PPV and NPV of most patient and CT procedural variables were high, even when including missing patient files in the analyses as falsely registered in the WDHR-CCTR.

Our finding of an increasing use of coronary CTA since 2008 is in accordance with other reports, ${ }^{12}$ and we expect this increase to continue in years to come. The lower completeness of cardiac CT procedures in the WDHR-CCTR when compared with the DNPR may be explained by the fact that cardiac CT examinations performed as a part of research projects and for planning of noncoronary interventions were not registered until recently in the WDHR-CCTR. In addition, cardiac CT procedures performed in children $<16$ years are not reported to the WDHR-CCTR.

To our knowledge, the only other large populationbased cardiac CT registry is the Coronary CT Angiography Evaluation for Clinical Outcomes: An International
Multicenter registry (CONFIRM). ${ }^{13}$ The CONFIRM Registry prospectively enrolls patients and procedural and outcome data from six countries in the world (USA, Germany, Canada, South Korea, Switzerland, and Italy). ${ }^{13}$ In 2012, the registry comprised more than 27,000 patients undergoing $\geq 64$-slice cardiac CT at 12 centers between 2003 and $2009 .{ }^{14}$ The CONFIRM registry is thus a valuable source to study the prognostic value of cardiac CT. ${ }^{14-16}$ However, complete follow-up of patients registered in CONFIRM is not possible, ${ }^{14,15}$ and outcome data are often collected retrospectively by, eg, telephone contact or email questionnaires. ${ }^{13-16}$ In comparison, the WDHR-CCTR is a semi-national, multicenter registry with detailed information on indication, patient characteristics, procedural data, CT outcome, and clinical consequence. It is based on data from both university and nonuniversity cardiac centers, making it representative for contemporary real-world cardiac CT practice. Individual-level data linkage (using the CPR number) to the Danish Civil Registration System enables complete patient follow-up with accurate accounting for censoring due to emigration or death. ${ }^{7}$ Moreover, linkage to other registries provides valuable information on comorbidity, socioeconomic data, and subsequent diagnostic and therapeutic resource utilization (including medication and interventions), clinical events, and mortality. ${ }^{4,6,8,17-19}$

Although our study overall supports the use of the WDHRCCTR for research, there are also limitations to be considered. During the study period, the database has continuously been optimized, ie, selected variables have changed from being optional to obligate for reporting to the WDHR-CCTR. These changes in reporting standards may in part explain some of the missing values over time, which reduced the overall completeness of some variables. We also found that although the completeness for radiation dose was greater than $90 \%$, the use and recording of different dose units to the registry may hamper the use of this variable for research.

The predictive values for the main patient and procedure variables examined in this study were found to be high. The variables systolic and diastolic blood pressures could be of interest when studying coronary CTA outcomes. Nonetheless, these variables were not validated because blood pressure most often is measured in relation to the cardiac CT examination and registered directly into WDHR-CCTR without further documentation in the medical records.

\section{Conclusion}

WDHR-CCTR provides ongoing prospective registration of all cardiac CTs performed in Western Denmark since 2008. Overall, the registry data have a high degree of completeness 
and validity, making it a valuable tool for clinical epidemiological research.

\section{Acknowledgments}

The study was supported by Aarhus University. The funding source had no role in the design, conduct, analysis, or reporting of the study.

\section{Author contributions}

MS conceived the study idea. LHN and MS designed the study and reviewed the literature. LP collected the data. MS directed the analyses, which was carried out by LHN. LHN performed medical record review, organized the writing, and wrote the initial draft. All authors participated in the discussion and interpretation of the results, critically revised the manuscript for intellectual content, and approved the final version before submission. LHN had full access to the data in the study and takes responsibility for the integrity of the data and the accuracy of the data analysis.

\section{Disclosure}

The authors report no conflicts of interest in this work.

\section{References}

1. Bonow RO, Mann DL, Zipes DP, Libby P. Braunwald's Heart Disease: a Textbook of Cardiovascular Medicine. 9th ed. Philadelphia, PA: Saunders; 2012.

2. Montalescot G, Sechtem U, Achenbach S, et al. 2013 ESC guidelines on the management of stable coronary artery disease: the Task Force on the management of stable coronary artery disease of the European Society of Cardiology. Eur Heart J. 2013;34(38):2949-3003.

3. Fihn SD, Gardin JM, Abrams J, et al. 2012 ACCF/AHA/ACP/AATS/ PCNA/SCAI/STS Guideline for the diagnosis and management of patients with stable ischemic heart disease: a report of the American College of Cardiology Foundation/American Heart Association Task Force on Practice Guidelines, and the American College of Physicians, American Association for Thoracic Surgery, Preventive Cardiovascular Nurses Association, Society for Cardiovascular Angiography and Interventions, and Society of Thoracic Surgeons. $\mathrm{J} \mathrm{Am} \mathrm{Coll} \mathrm{Cardiol.}$ 2012;60(24):e44-e164.

4. Schmidt M, Maeng M, Jakobsen CJ, et al. Existing data sources for clinical epidemiology: The Western Denmark Heart Registry. Clin Epidemiol. 2010;2:137-144.
5. The board of Western Denmark Heart Registry. Western Denmark Heart Registry: Annual Report 2008 (Data from 2007 and 2008) 2009.

6. Johannesdottir SA, Horvath-Puhó E, Ehrenstein V, Schmidt M, Pedersen L, Sørensen HT. Existing data sources for clinical epidemiology: The Danish National Database of Reimbursed Prescriptions. Clin Epidemiol. 2012;4:303-313.

7. Schmidt M, Pedersen L, Sørensen HT. The Danish Civil Registration System as a tool in epidemiology. Eur J Epidemiol. 2014;29(8): 541-549.

8. Lynge E, Sandegaard JL, Rebolj M. The Danish National Patient Register. Scand J Public Health. 2011;39(Suppl 7):30-33.

9. The Nordic Medico-Statistical Commitee (NOMESCO) Classification of Surgical Procedures. 2012. Available from: http://nowbase.org/ / media/Projekt\%20sites/Nowbase/Publikationer/NCSP/NCSP\%201_16. ashx.

10. Sørensen HT, Sabroe S, Olsen J. A framework for evaluation of secondary data sources for epidmiological researcjh. Int J Epidemiol. 1996;25(2):1075-1082.

11. Brown LD, Cai TT, DasGupta A. Interval estimation for a binomial proportion. Stat Sci. 2001;16(2):101-117.

12. Shaw LJ, Marwick TH, Zoghbi WA, et al. Why all the focus on cardiac imaging? JACC Cardiovasc Imaging. 2010;3(7):789-794.

13. Min JK, Dunning A, Lin FY, et al. Rationale and design of the CONFIRM (COronary CT Angiography EvaluatioN For Clinical Outcomes: An InteRnational Multicenter) Registry. J Cardiovasc Comput Tomogr. 2011;5(2):84-92.

14. Cho I, Chang HJ, Sung JM, et al. Coronary computed tomographic angiography and risk of all-cause mortality and nonfatal myocardial infarction in subjects without chest pain syndrome from the CONFIRM Registry (coronary CT angiography evaluation for clinical outcomes: an international multicenter registry). Circulation. 2012;126(3):304-313.

15. Min JK, Dunning A, Lin FY, et al. Age- and sex-related differences in all-cause mortality risk based on coronary computed tomography angiography findings results from the International Multicenter CONFIRM (Coronary CT Angiography Evaluation for Clinical Outcomes: An International Multicenter Registry) of 23,854 patients without known coronary artery disease. J Am Coll Cardiol. 2011;58:849-860.

16. Chow BJ, Small G, Yam Y, et al. Incremental prognostic value of cardiac computed tomography in coronary artery disease using CONFIRM: COroNary computed tomography angiography evaluation for clinical outcomes: an InteRnational Multicenter registry. Circ Cardiovasc Imaging. 2011;4(5):463-472.

17. Helweg-Larsen K. The Danish Register of Causes of Death. Scand J Public Health. 2011;39(Suppl 7):26-29.

18. Statistics Denmark. The IDA database. (In Danish: Den Integrerede Database for Arbejdsmarkedsforskning). 2012. Available from: http:// www.dst.dk/da/Statistik/dokumentation/kvalitetsdeklarationer/idadatabasen.aspx. Accessed September 1, 2014.

19. Gjerstorff ML. The Danish Cancer Registry. Scand J Public Health. 2011;39(Suppl 7):42-45. 


\section{Supplementary materials}

Table SI Variables included in the registration forms for the Western Denmark Cardiac Computed Tomography Registry

\begin{tabular}{|c|c|c|}
\hline \multicolumn{3}{|c|}{ Registration forms } \\
\hline Referral form & Medical history form & Procedure form \\
\hline CPR number & Family history of premature CAD & Type of CT scanner \\
\hline Sex & Current lipid-lowering therapy & $\begin{array}{l}\text { Cardiac CT indication (angina/equivalent, hear failure, visualization of valves and/or } \\
\text { aorta disease, visualization of stents, evaluation of cardiac structures, or others) }\end{array}$ \\
\hline County & Current medical treatment for hypertension & Angina type (if any): typical angina, atypical angina, unspecific chest pain, or dyspnea \\
\hline Area code & Smoking status & Priority (acute, subacute, or elective) \\
\hline \multirow[t]{24}{*}{ Referral date } & Diabetes & Date of procedure \\
\hline & Previous $\mathrm{PCl}$ & Kilo-electron volt \\
\hline & Previous cardiac surgery & Radiation dose (DLP) \\
\hline & Previous myocardial infarction & lodine dose $(\mathrm{mg})$ \\
\hline & Height $(\mathrm{cm})$ & Contrast volume $(\mathrm{mL})$ \\
\hline & Weight $(\mathrm{kg})$ & Contrast manufacturer \\
\hline & Creatinine level $(\mu \mathrm{mol} / \mathrm{L})$ & Beta-blocker (if any): name and administration \\
\hline & Systolic and diastolic blood & Heart rhythm (sinus rhythm, atrial fibrillation, supraventricular/ventricular \\
\hline & pressures $(\mathrm{mmHg})$ & premature beats/others) \\
\hline & Left ventricular ejection fraction $(\%)$ & Heart rate (bpm) \\
\hline & Cardiac devices & Ventriculography ejection fraction (\%) \\
\hline & Current medical treatments & Cardiac CT quality (good, moderate, or nonevaluable) \\
\hline & & Complications (descriptive) \\
\hline & & Vessel dominance (balanced, right, or left) \\
\hline & & CACS (Agatston score) result \\
\hline & & $\begin{array}{l}\text { Consequence of CACS results (termination or proceeding to contrast-enhanced } \\
\text { cardiac CT) }\end{array}$ \\
\hline & & Coronary CTA result (only CACS was performed, none CAD [0\% luminal stenosis], \\
\hline & & nonobstructive $\operatorname{CAD}[1 \%-49 \%$ luminal stenosis], obstructive $\mathrm{CAD}[\geq 50 \%$ luminal \\
\hline & & stenosis] categorized as: I-vessel obstructive CAD, 2-vessel obstructive CAD, \\
\hline & & 3-vessel/left main obstructive CAD) \\
\hline & & Consequence of coronary CTA results (none, medical treatment, referral to \\
\hline & & invasive coronary angiography, referral to myocardial perfusion imaging, referral \\
\hline & & to other noninvasive diagnostic testing, or other) \\
\hline & & Extracardiac findings (descriptive) \\
\hline
\end{tabular}

Abbreviations: CACS, coronary artery calcium scoring; CAD, coronary artery disease; CT, computed tomography; CTA, computed tomography angiography; CPR, Civil Personal Register; DLP, dose length product; PCl, percutaneous coronary intervention. 
Table S2 Variable values and reference standards used to validate data from the Western Denmark Coronary Computed Tomography Angiography Registry

\begin{tabular}{|c|c|}
\hline Variables & Values (reference standards for validation) \\
\hline Family history of premature CAD & Yes/no/unknown ${ }^{a}$ \\
\hline Current lipid-lowering therapy & Yes/no/unknown ${ }^{\mathrm{a}}$ \\
\hline Current medical treatment for hypertension & Yes/no/unknown ${ }^{\mathrm{a}}$ \\
\hline Smoking status & Current/never/former/unknown ${ }^{\mathrm{a}}$ \\
\hline Diabetes & $\begin{array}{l}\text { None/recently elevated blood glucose/insulin ( } \pm \text { oral antidiabetic treatment)/oral } \\
\text { antidiabetic treatment (without insulin)/nonpharmacological treatment/unknown }\end{array}$ \\
\hline Previous $\mathrm{PCl}$ & Yes/no/unknown ${ }^{\mathrm{a}}$ \\
\hline Previous cardiac surgery & Yes/no/unknown ${ }^{\mathrm{a}}$ \\
\hline Previous myocardial infarction & Yes/no/unknowna \\
\hline Height & Exact height in $\mathrm{cm}^{\mathrm{a}}$ \\
\hline Weight & Exact weight in $\mathrm{kg}^{\mathrm{a}}$ \\
\hline \multirow[t]{3}{*}{ Type of CT scanner } & Siemens 64-slice/Siemens 64-slice dual-source/Phillips 64-slice/Phillips 256-slice/GE 64-slice/ \\
\hline & Toshiba 64-slice/Toshiba 320-slice/Siemens Flash \\
\hline & GE $750 \mathrm{HD} /$ other $^{\mathrm{b}}$ \\
\hline Date of procedure & Day-month-year $( \pm \text { I week })^{\mathrm{b}}$ \\
\hline Kilo-electron volt & Exact kilo-electron volt ${ }^{\mathrm{b}}$ \\
\hline Radiation dose & Exact radiation dose in DLP/millisievert ${ }^{\mathrm{b}}$ \\
\hline Contrast volume & Exact volume in $\mathrm{mL}^{\mathrm{b}}$ \\
\hline CACS result & Exact score in Agatston ${ }^{b}$ \\
\hline Coronary CTA result & $\begin{array}{l}\text { Only CACS was performed/none CAD ( } 0 \% \text { luminal stenosis)/nonobstructive CAD } \\
\text { (I\%-49\% luminal stenosis)/obstructive CAD ( } \geq 50 \% \text { luminal stenosis) categorized as } \\
\text { l-vessel obstructive CAD/2-vessel obstructive CAD/3-vessel or left main obstructive } C A D^{a}\end{array}$ \\
\hline Consequence of coronary CTA results & $\begin{array}{l}\text { Nothing further/medical treatment/referral to invasive coronary angiography/referral to } \\
\text { myocardial perfusion imaging/referral to other noninvasive diagnostic testing/other }\end{array}$ \\
\hline
\end{tabular}

Notes: aReference standard: medical records; ${ }^{b}$ reference standard: medical records including imaging reports from working stations.

Abbreviations: CACS, coronary artery calcium scoring; CAD, coronary artery disease; CT, computed tomography; CTA, computed tomography angiography; DLP, dose length product; $\mathrm{PCl}$, percutaneous coronary intervention. 
Table S3 Characteristics of symptomatic patients in the coronary CTA cohort and patients in the randomly selected sample from the Western Denmark Cardiac Computed Tomography Registry, 2008-20I2

\begin{tabular}{|c|c|c|}
\hline & $\begin{array}{l}\text { Coronary } \\
\text { CTA cohort } \\
\text { overall } \\
(n=\mid 8,899)\end{array}$ & $\begin{array}{l}\text { Random } \\
\text { sample }^{a} \\
(n=250)\end{array}$ \\
\hline Male sex & $10,169(53.8)$ & $107(42.8)$ \\
\hline Age, years ${ }^{b}$ & $58(50-66)$ & $56.5(48-63)$ \\
\hline Family history of premature CAD & $7,353(38.9)$ & $97(38.8)$ \\
\hline Current lipid-lowering therapy & $5,883(3 \mathrm{I} . \mathrm{I})$ & $79(31.6)$ \\
\hline $\begin{array}{l}\text { Current medical treatment } \\
\text { for hypertension }\end{array}$ & $6,532(34.6)$ & $84(33.6)$ \\
\hline Smoking status (current or former) & $9,504(50.3)$ & |3| (52.4) \\
\hline Diabetes & $\mathrm{I}, 035(5.5)$ & $33(13.2)$ \\
\hline Previous PCl & $166(0.9)$ & 0 \\
\hline Previous cardiac surgery & $156(0.8)$ & I $(0.4)$ \\
\hline Previous myocardial infarction & $193(1.0)$ & 0 \\
\hline Height $(\mathrm{cm})^{\mathrm{b}}$ & I7I (I65-I78) & $171(158-184)$ \\
\hline Weight $(\mathrm{kg})^{\mathrm{b}}$ & $78(67-88)$ & $78(56-100)$ \\
\hline Creatinine level, $\mu \mathrm{mol} / \mathrm{L}^{\mathrm{b}}$ & $73(63-83)$ & $72(55-89)$ \\
\hline Systolic blood pressure, $\mathrm{mmHg}^{\mathrm{b}}$ & $140(|26-| 5 \mid)$ & $138(112-164)$ \\
\hline Diastolic blood pressure, $\mathrm{mmH} \mathrm{g}^{\mathrm{b}}$ & $81(75-90)$ & $80(65-95)$ \\
\hline Left ventricular ejection fraction ${ }^{\mathrm{b}}$ & $60(60-60)$ & $60(60-60)$ \\
\hline \multicolumn{3}{|l|}{ Angina type (if any) } \\
\hline Typical angina & I,764 (9.4) & $22(8.8)$ \\
\hline Atypical angina & $5,844(30.9)$ & $78(3 \mid .2)$ \\
\hline Unspecific chest pain & $4,760(25.2)$ & $58(23.2)$ \\
\hline Dyspnea & $916(4.8)$ & $8(3.2)$ \\
\hline Unknown & $5,615(29.7)$ & $84(33.6)$ \\
\hline \multicolumn{3}{|l|}{ Priority } \\
\hline Acute & $78(0.4)$ & $2(0.8)$ \\
\hline Subacute & $755(4.0)$ & $2(0.8)$ \\
\hline Elective & $17,209(91.1)$ & $230(92.0)$ \\
\hline Unknown & $857(4.5)$ & $16(6.4)$ \\
\hline Kilo-electron volt ${ }^{\mathrm{b}}$ & $100(100-120)$ & $120(100-120)$ \\
\hline Radiation dose & $-c$ & $-^{c}$ \\
\hline lodine concentration, $\mathrm{mg} / \mathrm{mL}^{\mathrm{b}}$ & $350(350-370)$ & $370(350-370)$ \\
\hline Contrast volume, $\mathrm{mL}^{\mathrm{b}}$ & $80(70-90)$ & 77.5 (70-90) \\
\hline Preprocedural beta-blocker & $|1,99|(63.4)$ & $164(65.6)$ \\
\hline \multicolumn{3}{|l|}{ Heart rhythm } \\
\hline Sinus rhythm & 17,794 (94.2) & $229(91.6)$ \\
\hline Atrial fibrillation & $108(0.6)$ & $2(0.8)$ \\
\hline
\end{tabular}

(Continued)
Table S3 (Continued)

\begin{tabular}{|c|c|c|}
\hline & $\begin{array}{l}\text { Coronary } \\
\text { CTA cohort } \\
\text { overall } \\
(n=18,899)\end{array}$ & $\begin{array}{l}\text { Random } \\
\text { sample }^{a} \\
(n=250)\end{array}$ \\
\hline Other & $85(0.4)$ & $2(0.8)$ \\
\hline Unknown & $912(4.8)$ & $17(6.8)$ \\
\hline Heart rate $(\mathrm{bpm})^{\mathrm{b}}$ & $59(54-64)$ & $60(55-65)$ \\
\hline \multicolumn{3}{|l|}{ Cardiac CT quality } \\
\hline Good & 14,304 (75.7) & I84 (73.6) \\
\hline Moderate & $\mathrm{I}, 897(10.0)$ & $20(8.0)$ \\
\hline Nonevaluable & $828(4.4)$ & $18(7.2)$ \\
\hline Unknown & $1,870(9.9)$ & $28(11.2)$ \\
\hline CACS (Agatston) result ${ }^{\mathrm{b}}$ & $0(0-90)$ & $0(0-75)$ \\
\hline \multicolumn{3}{|l|}{ Coronary CTA result } \\
\hline Normal & $12,550(66.4)$ & $164(65.6)$ \\
\hline Nonobstructive CAD & $2,213(11.7)$ & $39(15.6)$ \\
\hline I-vessel obstructive CAD & $2,012(10.6)$ & $19(7.6)$ \\
\hline 2-vessel obstructive CAD & $673(3.6)$ & $7(2.8)$ \\
\hline 3-vessel/LM obstructive CAD & $312(1.7)$ & $6(2.4)$ \\
\hline Only CACS performed & $427(2.3)$ & $6(2.4)$ \\
\hline Unknown & $712(3.7)$ & $9(3.6)$ \\
\hline \multicolumn{3}{|l|}{ Consequence of coronary } \\
\hline \multicolumn{3}{|l|}{ CTA results } \\
\hline Nothing further & $8,673(45.9)$ & $96(38.4)$ \\
\hline Medical treatment & $3,313(17.5)$ & $39(15.6)$ \\
\hline $\begin{array}{l}\text { Referral to invasive } \\
\text { coronary angiography }\end{array}$ & $3,216(17.0)$ & $42(16.8)$ \\
\hline $\begin{array}{l}\text { Referral to myocardial } \\
\text { perfusion imaging }\end{array}$ & $632(3.3)$ & $10(4.0)$ \\
\hline $\begin{array}{l}\text { CACS is too high - referral } \\
\text { to further testing }\end{array}$ & $157(0.8)$ & $\mathrm{I}(0.4)$ \\
\hline $\begin{array}{l}\text { Referral to other noninvasive } \\
\text { diagnostic testing }\end{array}$ & $399(2.1)$ & $9(3.6)$ \\
\hline Unknown & $2,509(\mid 3.4)$ & $53(21.2)$ \\
\hline
\end{tabular}

Notes: ${ }^{2} 250$ randomly selected symptomatic patients who underwent coronary CTA at three university cardiac centers (Aarhus, Aalborg, and Odense) and two nonuniversity cardiac centers (Lillebaelt Hospital-Vejle and Hospital of Southwestern Denmark-Esbjerg); 'values in median \pm interquartile range; ' was not estimated due to differences in registered dose units.

Abbreviations: CACS, coronary artery calcium scoring; CAD, coronary artery disease; CT, computed tomography; CTA, computed tomography angiography; $\mathrm{LM}$, left main; $\mathrm{PCl}$, percutaneous coronary intervention.
Clinical Epidemiology

\section{Publish your work in this journal}

Clinical Epidemiology is an international, peer-reviewed, open access, online journal focusing on disease and drug epidemiology, identification of risk factors and screening procedures to develop optimal preventative initiatives and programs. Specific topics include: diagnosis, prognosis, treatment, screening, prevention, risk factor modification,

\section{Dovepress}

systematic reviews, risk \& safety of medical interventions, epidemiology \& biostatistical methods, and evaluation of guidelines, translational medicine, health policies \& economic evaluations. The manuscript management system is completely online and includes a very quick and fair peer-review system, which is all easy to use. 